Pflügers Arch (1992) $421: 155-162$

\title{
Disparate effects of calcium channel blockers on pressure dependence of renin secretion and flow in the isolated perfused rat kidney
}

\author{
Holger Scholz ${ }^{1, *}$ and Armin Kurtz ${ }^{2}$ \\ 1 Physiologisches Institut der Universität, Winterthurerstrasse 190, CH-8057 Zürich, Switzerland \\ ${ }^{2}$ Institut für Physiologie I, Universität Regensburg, W-8400 Regensburg, Federal Republic of Germany
}

Received November 12, 1991/Received after revision February 26, 1992/Accepted March 30, 1992

\begin{abstract}
Using the model of isolated perfused rat kidneys this study was performed to investigate whether or not voltage-operated calcium channels are essentially involved in the pressure control of renin secretion from the kidneys. At a perfusion pressure of $100 \mathrm{~mm} \mathrm{Hg}(13.3 \mathrm{kPa})$ renin secretory rates were $4.2 \pm 0.7\left(\right.$ ng angiotensin $\mathrm{I} \mathrm{h}^{-1}$ ) $\min ^{-1} \mathrm{~g}^{-1}$. Stepwise reduction of renal perfusion pressure to 80,60 , and $40 \mathrm{~mm} \mathrm{Hg}(10.6,8.0,5.3 \mathrm{kPa})$ resulted in an increase of renin release yielding a 30 -fold stimulation at $40 \mathrm{~mm} \mathrm{Hg}$ vs $100 \mathrm{~mm} \mathrm{Hg}$. Increasing the perfusion pressure above $100 \mathrm{~mm} \mathrm{Hg}$ did not further significantly decrease renin secretion. The perfusate flow rate was also pressure-dependent. Flow rates increased linearly with pressure and reached a plateau at $100 \mathrm{~mm} \mathrm{Hg}$, which was maintained up to $160 \mathrm{~mm} \mathrm{Hg}(21.3 \mathrm{kPa})$. The averaged flow rate at the plateau was $15.5 \mathrm{ml} \mathrm{min}^{-1} \mathrm{~g}^{-1}$. In the presence of the three different calcium antagonists nifedipine $(5 \mu \mathrm{M})$, nitrendipine $(3 \mu \mathrm{M})$ and verapamil $(5 \mu \mathrm{M})$, myogenic autoregulation of flow was abolished as indicated by the rise of the pressure/flow curve between 40 and $160 \mathrm{~mm} \mathrm{Hg}$. At the same time, however, these calcium channel blockers did not alter the relationship between perfusion pressure and renin secretion. Moreover, the calcium channel agonist Bay K $8644(5 \mu \mathrm{M})$ caused a strong and long-lasting vasoconstriction, without changing renin secretion. Taken together, our findings indicate that organic calcium antagonists at concentrations sufficient to block voltage-operated calcium channels in vascular smooth muscle cells have no influence on the pressure-dependent control of renin secretion. In consequence, it appears unlikely that voltage-operated calcium channels are essentially involved in the signal transduction mechanism that links renin secretion and blood pressure.
\end{abstract}

Key words: Renal vascular tone - Calcium channels Juxtaglomerular cells

\footnotetext{
* Present address: Institut für Physiologie I, Universität Regensburg, W-8400 Regensburg, FRG

Offprint requests to: $\mathrm{H}$. Scholz
}

\section{Introduction}

Since the original work by Goldblatt [10] it has been well established that the blood pressure is an essential control factor for the secretion of renin from the kidneys $[7,17$, $20,34,38]$. Within the kidneys renin is released from the juxtaglomerular epitheloid (JG) cells, which are metaplastically transformed vascular smooth muscle cells located in the media layer of afferent arterioles $[2,36]$. The cellular mechanisms by which a drop of blood pressure enhances the secretion and an increase of pressure inhibits the secretion of renin are not well understood. Tobian [37] proposed the existence of a renal "baroreceptor" that responds to stretching of the afferent arteriole. This idea was further developed by Fray [8], who presented a mathematical stretch receptor model based on his studies of the perfused rat kidney. According to this model it has been suggested that the intraluminal pressure in the afferent arterioles has influence on the stretch of the smooth muscle cells in the media layer. Tension of renal vascular smooth muscle cells leads to membrane depolarization [15] and in consequence to the activation of voltageoperated calcium channels (VOCC), which mediate transmembrane calcium influx and an increase of the cytosolic concentration of calcium (cf. [18]). A rise of intracellular calcium is the key event for smooth muscle cell contraction. It is likely, therefore, that this sequence of events provides the explanation for the myogenic autoregulation of renal flow [18]. Since JG cells are transformed vascular smooth muscle cells and since calcium is considered as an inhibitory signal for renin secretion (cf. [14]) it has been speculated that a similar mechanism involving the activation of VOCC also mediates the control of renin secretion by the pressure [9]. Experimental evidence for a functional role of VOCC in JG cells, however, is not unequivocal. On the one hand there are findings showing that the pressure effect on renin secretion is attenuated by the calcium channel blocker verapamil ([9], cf. [14]). On the other hand there are also findings that verapamil can even inhibit renin secretion in dog kidneys [28]. Moreover, evidence for a functional role of dihydropyridine- 
sensitive calcium channels in the control of renin secretion from isolated rat kidneys is controversial $[6,13,16,24]$.

In order to get basic information about the cellular mechanisms underlying the renal baroreceptor controlling renin release it appeared reasonable to examine thoroughly the functional role of VOCC in this process. For control it also seemed meaningful to monitor renal vascular resistance in parallel, because this parameter is known to be strongly dependent on the activity of VOCC. We have recently shown that the isolated rat kidney is a suitable model for the study of renin secretion and renal vascular resistance in parallel [31]. With this model we have therefore examined the effects of organic calcium antagonists and agonists on the pressure dependence of renin secretion and flow.

We found that organic calcium channel blockers abolished the pressure-induced changes in renal vascular resistance. Neither calcium channel agonists nor antagonists, however, had influence on pressure-dependent renin secretion.

\section{Materials and methods}

Male SIV strain rats $(250-350 \mathrm{~g}$ body weight), having free access to commercial pellet chow and tap water, were obtained from the local animal house and used throughout. Kidney perfusion was performed in a recycling system according to the technique of Schurek and Alt [33] as described in detail previously [31]. In brief: the animals were anaesthetized with $150 \mathrm{mg} \mathrm{kg} \mathrm{kg}^{-1}$ 5-ethyl-(1'methylpropyl)-2-thiobarbituric acid (Inactin, Byk Gulden, Konstanz, FRG). Volume loss during the preparation was compensated by intermittent injections of physiological saline (about $2.5 \mathrm{ml}$ totally) via a catheter that was inserted into the jugular vein. After opening of the abdominal cavity by a midline incision the right kidney was exposed and placed in a thermostatically controlled metal chamber. The right ureter was cannulated with a small polypropylene tube (PP-10), which was connected to a larger polyethylene catheter (PE-50). After intravenous heparin injection ( $2 \mathrm{U}$ $\mathrm{g}^{-1}$, Liquemin, Roche, Basel, Switzerland) the aorta was clamped distal to the right renal artery and the large vessels branching off the abdominal aorta were ligated. A double-barrelled cannula was inserted into the abdominal aorta and placed close to the origin of the right renal artery. After ligation of the aorta proximal to the right renal artery the aortic clamp was quickly removed and perfusion was started in situ with an initial flow rate of $8 \mathrm{ml} \mathrm{min}{ }^{-1}$. The right kidney was excised and perfusion at constant pressure $(100 \mathrm{~mm} \mathrm{Hg}$, $13.3 \mathrm{kPa}$ ) was established. To this end renal artery pressure was monitored through the inner part of the perfusion cannula (Statham transducer P 10 EZ) and the pressure signal was used for feedback control of a peristaltic pump. The perfusion circuit was closed by draining the renal venous effluent via a metal cannula back into a reservoir $(200-220 \mathrm{ml})$. The basic perfusion medium, which was taken from the thermostated $\left(37^{\circ} \mathrm{C}\right)$ reservoir, consisted of a modified Krebs-Henseleit solution containing all physiological amino acids in concentrations between $0.2 \mathrm{mM}$ and $2.0 \mathrm{mM}$ plus $8.7 \mathrm{mM}$ glucose, $0.3 \mathrm{mM}$ pyruvate, $2.0 \mathrm{mM}$ L-lactate, $1.0 \mathrm{mM}$ 2-oxoglutarate, $1.0 \mathrm{mM}$ L-malate and $6.0 \mathrm{mM}$ urea. The perfusate was supplemented with $6 \mathrm{~g} / 100 \mathrm{ml}$ bovine serum albumin, $0.1 \mathrm{~g} / 100 \mathrm{ml}$ inulin, and with freshly washed human red blood cells $(10 \pm 2 \%$ haematocrit). Ampicillin $(3 \mathrm{mg} / 100 \mathrm{ml})$ and flucloxacillin $(3 \mathrm{mg} /$ $100 \mathrm{ml}$ ) were added to inhibit possible bacterial contamination of the medium. To improve the functional preservation of the preparation, the perfusate was continuously dialysed against a 25 -fold volume of the same composition but without erythrocytes and albumin. For oxygenation of the perfusion medium the dialysate was gassed with a $95 \%$ oxygen, $5 \%$ carbon dioxide mixture. Perfusate flow rate was obtained from the revolutions of the peristaltic pump, which was calibrated before and after each experiment. Renal flow rate and perfusion pressure were continuously monitored by a potentiometric recorder (Kipp \& Zonen, Delft, Netherlands). Stock solutions of the drugs to be tested (see below) were dissolved in freshly prepared perfusate and infused into the arterial limb of the perfusion circuit directly before the kidneys (peristaltic pump 2132 Microperpex, LKB, Bomma, Sweden) at $1 \%$ of the rate of perfusate flow. For determination of perfusate renin activity (pRA) aliquots (about $100 \mu \mathrm{l}$ ) were drawn from the arterial limb of the circulation and the renal venous effluent. The samples were centrifuged $\left(4^{\circ} \mathrm{C}\right)$ at $1500 \mathrm{~g}$ for $15 \mathrm{~min}$ (Sorvall RT 6000) and the supernatants were stored at $-20^{\circ} \mathrm{C}$ until assayed for renin activity.

Experimental protocol. After a 25 -min equilibration period at constant perfusion pressure of $100 \mathrm{~mm} \mathrm{Hg}$, renal artery pressure was increased stepwise $(20 \mathrm{~mm} \mathrm{Hg})$ to 120,140 , and $160 \mathrm{~mm} \mathrm{Hg} \mathrm{(16,}$ 18.6 and $21.3 \mathrm{kPa}$ ). Each pressure level was maintained for $5 \mathrm{~min}$ and perfusate samples for determination of renin activity were taken after 1, 3 and $5 \mathrm{~min}$. From the maximum of $160 \mathrm{~mm} \mathrm{Hg}$, renal perfusion pressure was first returned to $100 \mathrm{~mm} \mathrm{Hg}$ and, after a 5min period, was lowered stepwise to 80,60 , and $40 \mathrm{~mm} \mathrm{Hg}(10.6$, $8.0,5.3 \mathrm{kPa}$ ) in the same way as it had previously been increased to $160 \mathrm{~mm} \mathrm{Hg}$. Controls and the experiments with calcium antagonists were performed with the same kidney preparations.

Determination of renin activity. Perfusate samples were incubated for $1.5 \mathrm{~h}$ at $37^{\circ} \mathrm{C}$ with plasma of bilaterally nephrectomized male rats as renin substrate [27]. The angiotensin I generated was determined by radioimmunoassay (Medipro AG, Teufen, Switzerland).

Renin release. In a previous study performed with the same experimental model we have found that renin is not inactivated during its passage through isolated perfused rat kidneys [31]. Therefore, renin secretory rates could be calculated from the arteriovenous differences of perfusate renin activity and the corresponding renal flow rates.

Determination of sodium and potassium. Sodium and potassium concentrations were measured in perfusate and urine samples by means of a flame photometer equipped with an internal caesium standard (Instrumentation Laboratory 943).

Calculation of glomerular filtration rate. The glomerular filtration rate was calculated from the inulin clearance. Following acid hydrolysis of inulin, the fructose concentration was measured spectrophotometrically according to the method described by Schmidt [30].

Agents, Pyruvate and the kit for fructose determination were obtained from Boehringer, Mannheim, FRG. Ampicillin and flucloxacillin were from Beecham, Bern, Switzerland. Glutamate, urea, and 2-oxoglutarate were obtained from Merck, Darmstadt, FRG. L-Malic acid and L-lactate as sodium salts were provided by Serva, Heidelberg, FRG. L-Amino acids were from Braun/Melsungen, FRG (Aminoplasmal paediatric free of carbon hydrate). Inulin was provided by Laevosan, Linz, Austria. Nifedipine, verapamil, angiotensin II, isoproterenol, bumetanide and bovine serum albumin (fraction $V$ powder) were purchased from Sigma International. Bay K 8644 and nitrendipine were provided by Bayer, Leverkusen, FRG. Stock solutions of the drugs to be tested were $0.1 \mathrm{M}$ in dimethylsulphoxide. The final dimethylsulphoxide concentration in the perfusion medium was less than $0.01 \%$.

Statistics. Levels of significance were calculated by using Student's $t$-test. $P<0.05$ was considered significant.

\section{Results}

Kidneys were usually perfused in vitro for $2 \mathrm{~h}$. In order to perceive a possible functional instability of the prep- 
Table 1. Parameters of excretory kidney function ${ }^{\mathrm{a}}$

\begin{tabular}{lrrr}
\hline Parameter & 30 min & $60 \min$ & \multicolumn{1}{c}{$90 \mathrm{~min}$} \\
\hline Urine flow rate & & & \\
$\quad\left(\mu l \min ^{-1} \mathrm{~g}^{-1}\right)$ & $43 \pm 5$ & $58 \pm 7$ & $96 \pm 11$ \\
$\mathrm{GFR}\left(\mu \mathrm{min} \mathrm{min}^{-1} \mathrm{~g}^{-1}\right)$ & $958 \pm 12$ & $961 \pm 10$ & $967 \pm 12$ \\
$\mathrm{~T}_{\mathrm{Na}}(\%$ of filtered load $)$ & $95 \pm 2$ & $92 \pm 3$ & $87 \pm 2$ \\
\hline
\end{tabular}

a Isolated rat kidneys were perfused at renal artery pressure of $100 \mathrm{~mm} \mathrm{Hg}(13.3 \mathrm{kPa})$. Urine samples for determination of glomerular filtration rate (GFR) and tubular sodium reabsorption $\left(\mathrm{T}_{\mathrm{Na}}\right)$ were collected at 30,60 and $90 \mathrm{~min}$ after the onset of perfusion. Values are means \pm SEM of ten experiments

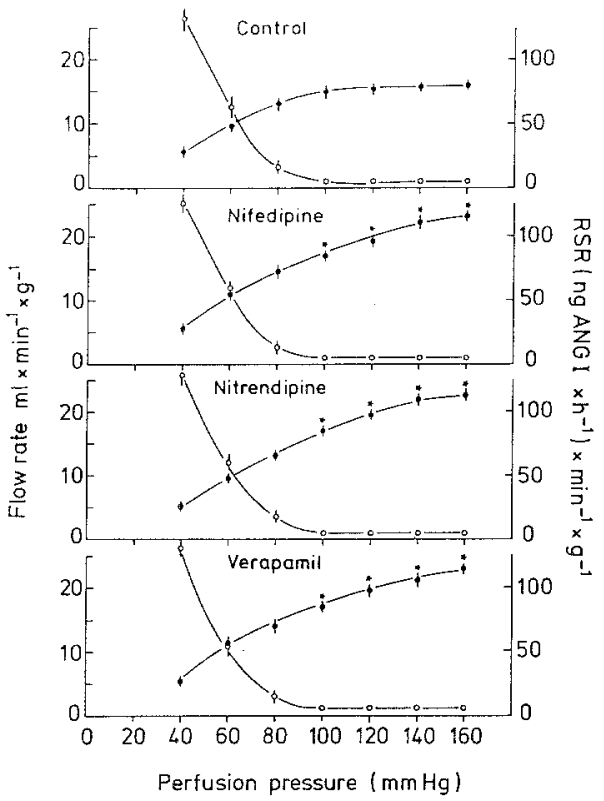

Fig. 1. Pressure/flow relationship (๑) and pressure-dependent renin release $(O)$ from isolated perfused rat kidneys run under control conditions (upper panel). Renin secretory rates (RSR) at distinct pressure levels were calculated from the arteriovenous difference of renin activity of perfusate and from the corresponding renal flow rates $(A N G$, angiotensin). Values are means \pm SEM from ten different experiments. Lower panels: effect of nifedipine $(5 \mu \mathrm{M})$, nitrendipine $(3 \mu \mathrm{M})$ and verapamil $(5 \mu \mathrm{M})$, three different organic calcium channel blockers, on renal autoregulation of flow and renin secretory rates. The drugs were continuously infused in to the arterial limb of the circulation with a rate of $1 \%$ of renal perfusate flow. Values are means \pm SEM, $n=5$. $\star$, Significantly different from control $(P<0.05)$

arations we also determined excretory kidney function. To this end, urine samples were collected half-hourly and glomerular filtration rate and tubular sodium reabsorption were determined. Values for urine flow rates, glomerular filtration rates and sodium reabsorption are listed in Table 1.

During control periods, when kidneys were perfused at a renal artery pressure of $100 \mathrm{~mm} \mathrm{Hg}$, flow rates were $14.9 \pm 0.4 \mathrm{ml} \mathrm{min}^{-1} \mathrm{~g}^{-1}$ (mean $\pm \mathrm{SEM} ; n=10$ ) (Fig. 1 , upper panel). A stepwise increase of perfusion pressure to values of 120,140 and $160 \mathrm{~mm} \mathrm{Hg}$ caused slight but not significant $(P>0.05)$ increases of flow rates to $15.3 \pm 0.6$, $15.8 \pm 0.5$ and $16.1 \pm 0.7 \mathrm{ml} \mathrm{min}^{-1} \mathrm{~g}^{-1}$ respectively
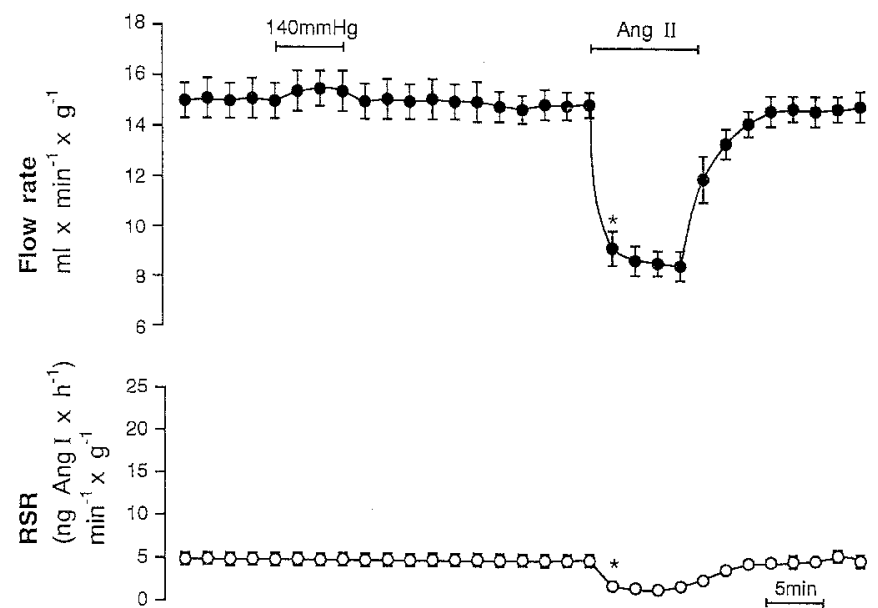

Fig. 2. Effect of of increasing renal artery pressure from 100 to $140 \mathrm{~mm} \mathrm{Hg}$ and of angiotensin II (Ang II) $(100 \mathrm{pM})$ on renal flow rate and renin release. Values are means $\pm \mathrm{SEM}, n=5$. $\star$, Significantly different from control $(P<0.05)$

(Fig. 1). Reductions of renal artery pressure to 80,60 and $40 \mathrm{~mm} \mathrm{Hg}$, on the other hand, resulted in almost linear decreases of perfusate flow to $12.8 \pm 0.8,9.4 \pm 0.5$ and $5.5 \pm 0.3 \mathrm{ml} \mathrm{min}^{-1} \mathrm{~g}^{-1}$ respectively (Fig. 1).

Renin secretion rates at $100 \mathrm{~mm} \mathrm{Hg}$ were $4.2 \pm 0.7$ (ng angiotensin $\mathrm{I} \mathrm{h}^{-1}$ ) $\min ^{-1} \mathrm{~g}^{-1}$ (mean $\left.\pm \mathrm{SEM}, n=10\right)$ (Fig. 1, upper panel). A stepwise increase of perfusion pressure to 120,140 and $160 \mathrm{~mm} \mathrm{Hg}$ did not further significantly inhibit renin release (Fig. 1). Nonetheless, renin secretion was still inhibitable by angiotensin II $(100 \mathrm{pM})$ and could be stimulated by isoproterenol $(10 \mathrm{nM})$ within this pressure range (Figs. 2 and 8).

Stepwise reductions of renal artery pressure below $100 \mathrm{~mm} \mathrm{Hg}$ were paralleled by exponential increases of renin secretory rates. At pressure values of 80,60 and $40 \mathrm{~mm} \mathrm{Hg}$, renin secretion rates were $16 \pm 3,63 \pm 8$ and $129 \pm 10$ (ng angiotensin $\mathrm{I} \mathrm{h}^{-1}$ ) $\min ^{-1} \mathrm{~g}^{-1}$ respectively $(n=10)$ (Fig. 1). Enhancement of renin secretion by a reduction of perfusion pressure was of rapid onset and was apparent within the first $2 \mathrm{~min}$ after the drop of pressure (Fig. 3).

The organic calcium channel blocker nifedipine $(5 \mu \mathrm{M})$ caused significant increases of renal flow rates $(P<0.05)$ in the pressure range $100-160 \mathrm{~mm} \mathrm{Hg}(n=5)$ (Fig. 1). Perfusate flow rates in the presence of nifedipine $(5 \mu \mathrm{M})$ were $17.1 \pm 0.5,19.2 \pm 1.0,22.0 \pm 0.6$ and $22.9 \pm 0.5 \mathrm{ml} \mathrm{min}^{-1} \mathrm{~g}^{-1}$ at pressures of $100,120,140$ and $160 \mathrm{~mm} \mathrm{Hg}$ respectively. Flow rates at 80,60 and $40 \mathrm{~mm}$ $\mathrm{Hg}$ were not significantly altered by nifedipine (Fig. 1). At the same time nifedipine did not significantly affect pressure-modulated renin secretion rates in the range $40-160 \mathrm{~mm} \mathrm{Hg}$ (Fig. 1). At concentrations higher than $5 \mu \mathrm{M}$, nifedipine $(25 \mu \mathrm{M}, 50 \mu \mathrm{M})$ did not further decrease renal vascular resistance and also did not stimulate renin release (Fig. 4). In addition to the renal vascular relaxation, nifedipine $(5 \mu \mathrm{M})$ also increased urinary sodium excretion from $7.7 \pm 0.5 \mu \mathrm{mol} \mathrm{min}{ }^{-1} \mathrm{~g}^{-1}$ under control conditions to maximally $11.8 \pm 0.9 \mu \mathrm{mol} \mathrm{min}{ }^{-1} \mathrm{~g}^{-1}$ at a perfusion pressure of $100 \mathrm{~mm} \mathrm{Hg}$. A rise of the sodium chloride load at the macula densa acts as an inhibitory 

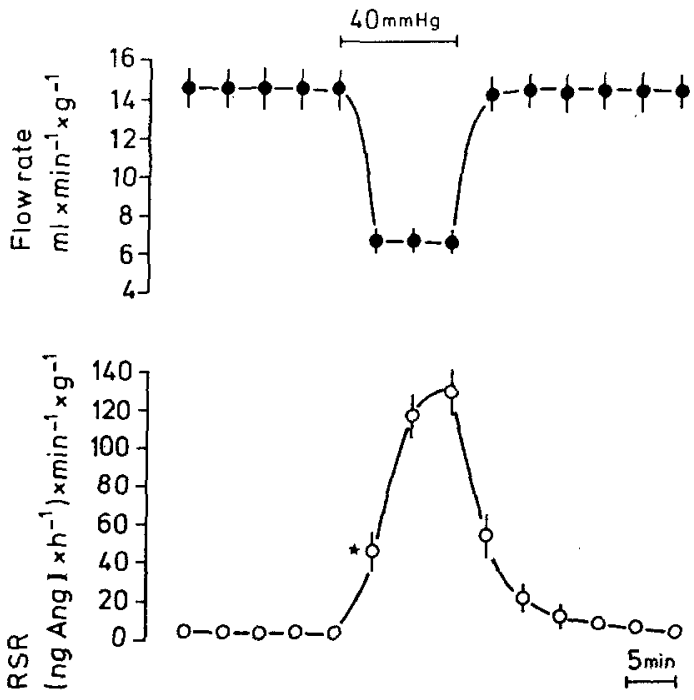

Fig. 3. Time courses of renal flow rate and renin secretion rate in response to decreasing perfusion pressure from 100 to $40 \mathrm{~mm} \mathrm{Hg}$ $(13.3$ to $5.3 \mathrm{kPa})$. Values are means $\pm \mathrm{SEM}, n=10$. $\star$, Significantly different from control

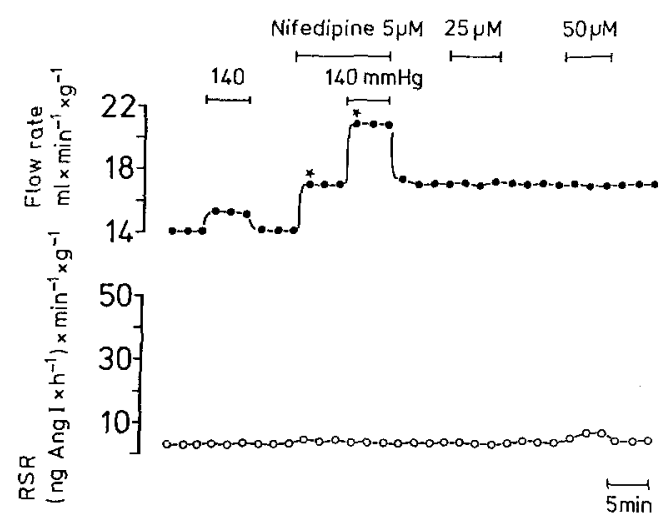

Fig. 4. Dose-dependent effects of the dihydropyridine calcium antagonist nifedipine on renal flow and renin secretory rates at pressure values of $100 \mathrm{~mm} \mathrm{Hg}$ and $140 \mathrm{~mm} \mathrm{Hg}$ (13.3 and $18.6 \mathrm{kPa}$ ). Values are means from three different experiments. $\star$, Significantly different from control $(P<0.05)$

signal for renin secretion [35]. It appears, therefore, not unlikely that nifedipine stimulated renin release from renal JG cells directly via inhibition of VOCC and at the same time decreased renin secretion by activating the inhibitory macula densa mechanism. As a consequence, the net amount of renin released from JG cells would be unchanged. To test for the latter possibility we used bumetanide, an inhibitor of the macula densa $\mathrm{Na}^{+}-\mathrm{K}^{+}$$2 \mathrm{Cl}^{-}$cotransport [11]. As shown in Fig. 5, bumetanide $(50 \mu \mathrm{M})$ increased the basal flow rate from $15.8 \pm 0.5$ to $17.0 \pm 0.5 \mathrm{ml} \mathrm{min}^{-1} \mathrm{~g}^{-1}$ and renin secretory rates from $5.0 \pm 0.8$ to $12 \pm 1.2$ (ng angiotensin $I^{-1}$ ) $\mathrm{min}^{-1} \mathrm{~g}^{-1}$. Those effects of bumetanide were paralleled by an increase of urinary sodium excretion from $6.5 \pm 0.5$ to $26.4 \pm 2.0 \mu \mathrm{mol} \mathrm{min}{ }^{-1} \mathrm{~g}^{-1}$. However, nifedipine $(5 \mu \mathrm{M})$ even in the presence of $50 \mu \mathrm{M}$ bumetanide did not significantly affect renin secretion (Fig. 5).

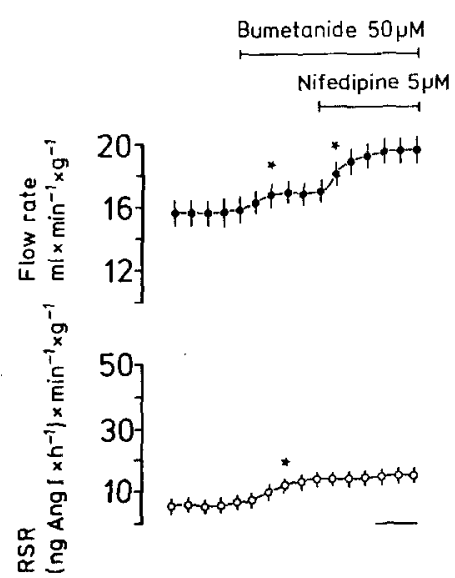

Fig. 5. Effect of nifedipine $(5 \mu \mathrm{M})$ on renal flow and renin secretion in the presence of $50 \mu \mathrm{M}$ bumetanide, an inhibitor of the macula densa $\mathrm{Na}^{+}-\mathrm{K}^{+}-2 \mathrm{Cl}^{-}$cotransport. Perfusion pressure was held constant at $100 \mathrm{~mm} \mathrm{Hg}$. Values are means $\pm \mathrm{SEM}, n=5$. $\star$, Significantly different from control $(P<0.05)$. The bar indicates $5 \mathrm{~min}$ on the time axis

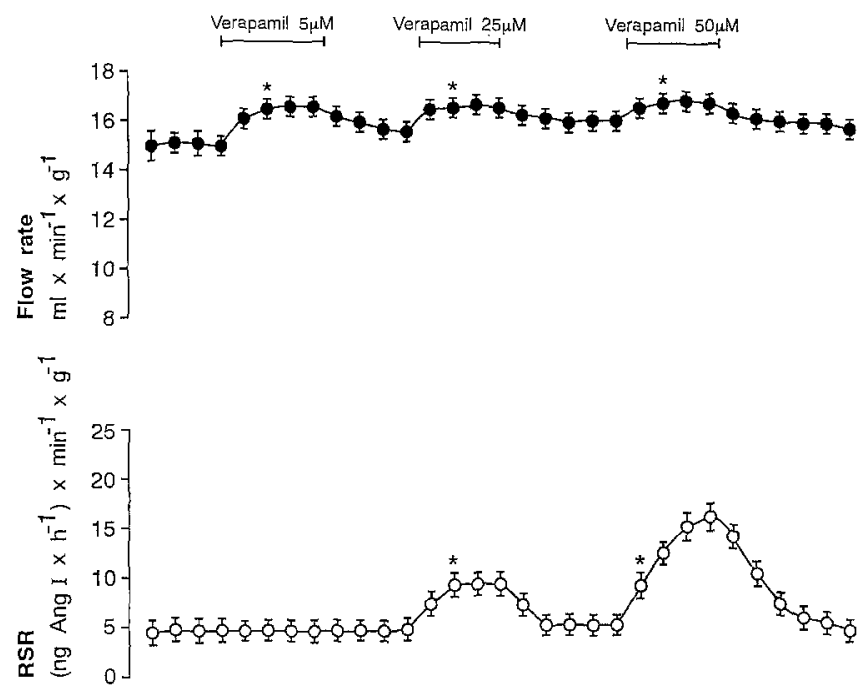

Fig. 6. Dose/response curves of the organic calcium channel blocker verapamil. Perfusion pressure was held constant at $100 \mathrm{~mm} \mathrm{Hg}$. Values are means $\pm \mathrm{SEM}, n=5$. $\star$, Significantly different from control $(P<0.05)$

Like nifedipine, nitrendipine, another dihydropyridine derivative [1] used at a concentration of $3 \mu \mathrm{M}$, significantly increased renal flow rate at pressure values of 100 , 120,140 , and $160 \mathrm{~mm} \mathrm{Hg}$ resulting in an almost linear pressure/flow curve $(n=5)$ (Fig. 1). Like nifedipine, nitrendipine did not significantly affect pressure-dependent renin release (Fig. 1). Verapamil at $5 \mu \mathrm{M}$ [1] also abolished renal autoregulation of flow but had no effect on the relationship between renin secretion and perfusion pressure (Fig. 1). At higher concentrations verapamil led to a moderate and dose-dependent increase of renin secretion at $100 \mathrm{~mm} \mathrm{Hg}$ (Fig. 6).

To evaluate further the potential role of VOCC in the control of renin secretion, we used Bay $K$ 8644, a dihydropyridine calcium channel agonist [32] to enhance transmembrane calcium influx through voltage-operated 

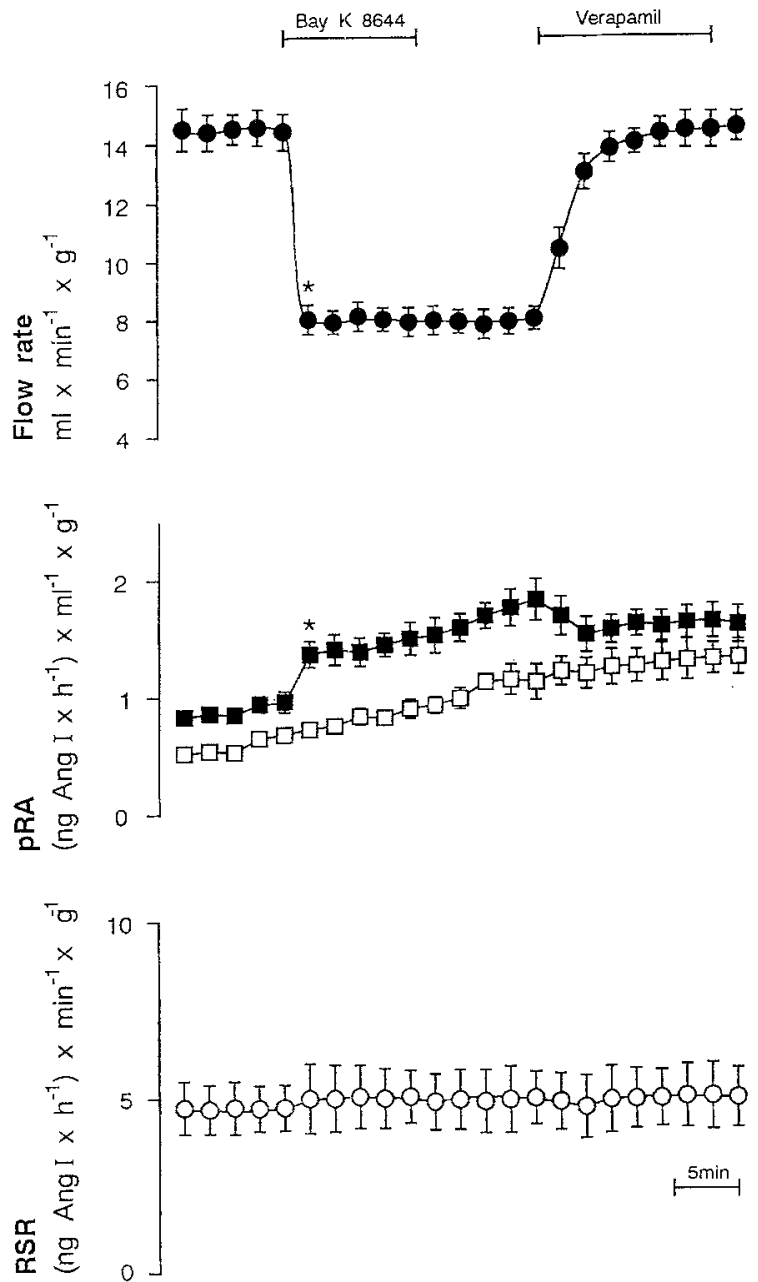

Fig. 7. Action of Bay K $8644(5 \mu \mathrm{M})$ on basal flow and renin secretory rates from isolated rat kidneys perfused at constant pressure of $100 \mathrm{~mm} \mathrm{Hg}$. The middle trace indicates the renin activities in the arterial $(\square)$ and the venous ( $\square$ ) perfusate. The long-lasting vasoconstricting effect of Bay K 8644 was completely reversed by verapamil $(5 \mu \mathrm{M})$. Values are means $\pm \mathrm{SEM}, n=5$. $\star$, Significantly different from control $(P<0.05)$

calcium channels. As shown in Fig. 7 Bay K 8644 ( $5 \mu \mathrm{M})$ caused a prompt and long-lasting decrease of renal flow rate from $14.8 \pm 0.7$ to $8.2 \pm 0.4 \mathrm{ml} \mathrm{min}^{-1} \mathrm{~g}^{-1}$ when kidneys were perfused at $100 \mathrm{~mm} \mathrm{Hg}$, and this vasoconstriction was completely reversed by verapamil $(5 \mu \mathrm{M})$. The vasoconstrictor action of Bay K 8644 was paralleled by an increase of the arteriovenous difference of renin activity in the perfusate in such a way that Bay K 8644 did not significantly affect renin secretion (Fig. 7). Bay $\mathrm{K} 8644(5 \mu \mathrm{M})$ also had no effect on renin secretion stimulated by isoproterenol (10 nM) (Fig. 8).

\section{Discussion}

Pressure-dependent renin secretion from renal juxtaglomerular (JG) cells makes an important contribution to the homeostasis of systemic blood pressure [12]. The cellular baroreceptor mechanism that leads to stimulation of renin secretion when renal artery pressure falls is still

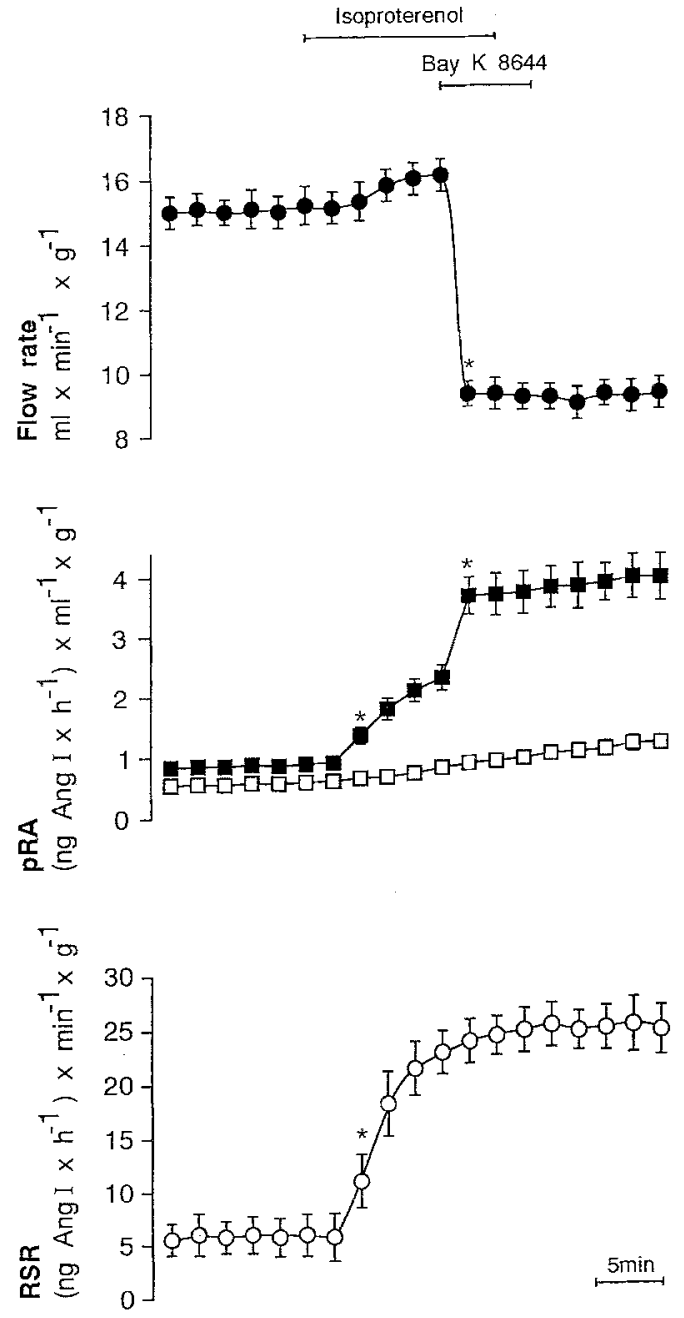

Fig. 8. Effect of Bay K $8644(5 \mu \mathrm{M})$ on flow rates and renin secretion rates from isolated kidneys stimulated with isoproterenol $(10 \mathrm{nM})$. In the middle trace are shown the renin activities in the arterial ( $\square$ ) and the venous $(\boldsymbol{D})$ perfusate. Values are means $\pm \operatorname{SEM}, n=5$. $\star$, Significantly different from control $(P<0.05)$

unknown. From the finding that pressure-controlled renin release is also preserved in non-filtering kidneys it was concluded that renal "baroreception" resides in the renal vasculature rather than being related to tubular, in particular to the macula densa, function (cf. [14]).

In parallel to the inhibition of renin secretion a rise of renal perfusion pressure also causes an increase of renal vascular tone thus keeping blood flow through the kidneys constant over a wide pressure range, a phenomenon referred to as the renal autoregulation of flow [18].

Since JG cells develop from vascular smooth muscle cells by reversible metaplastic transformation $[2,36]$, it is not unlikely that both renin secretion and myogenic control of vascular tone could primarily be controlled by a similar cellular signal transduction mechanism (cf. [14]). In fact, a number of vasoconstrictor agents such as angiotensin II have been found to inhibit renin release from JG cells, whereas renal vasodilators such as isoproterenol stimulate renin secretion $[13,14]$ suggesting that the amount of renin released from JG cells is in- 
versely related to the state of tension of renal vascular smooth muscle cells.

The cellular mechanisms underlying myogenic control of vascular tone are not yet completely understood. Renal autoregulation of flow in vivo and in vitro, however, was blunted by organic calcium channel blockers [4, 23, 25] suggesting that voltage-operated calcium channels (VOCC) are somehow involved in the pressure control of vascular resistance. On the other hand, an increase of the intracellular calcium concentration is believed to act as an inhibitory signal for renin secretion from JG cells [13, 14] and it is still an open question whether transmembrane calcium influx through VOCC contributes to this phenomenon.

In our study we have therefore tested for a functional role of VOCC in the pressure control of renin secretion. To this end we have used the model of isolated perfused rat kidneys because this preparation allows pharmacological effects on renal function to be monitored under controlled in vitro conditions. Since functional deterioration of cell-free perfused isolated kidney preparations has been reported to be at least in part prevented by increasing the oxygen supply to the kidneys [22], a $10 \%$ fraction of human red cells was added to the perfusate. In previous studies pressure-dependent renin secretion and autoregulation of flow have been found to be rather well preserved under these conditions [38]. In addition, the perfusion medium was regenerated by continuous dialysis during the experiments and the comparably low urine flow rates and the relatively high reabsorption rate for sodium argue in favour for the functional conservation of the isolated kidneys. Our finding that decreasing perfusion pressure in the range $80-40 \mathrm{~mm} \mathrm{Hg}$ resulted in a linear pressure/flow relationship (Fig. 1) suggests that the renal vasculature was maximally dilated and myogenic regulation of vascular tone was absent in this pressure range. At the same time, pressure-dependent renin secretion was well preserved corresponding to an increase of secretion rate of approximately 2.8 (ng angiotensin $\mathrm{I} \mathrm{h}^{-1}$ ) $\min ^{-1} \mathrm{~g}^{-1} \mathrm{~mm} \mathrm{Hg}{ }^{-1}$ when renal artery pressures were lowered to values below $80 \mathrm{~mm} \mathrm{Hg}$ (Fig. 1). This suggests that renin release was not related to renal vascular tone within this range of perfusion pressure, a finding that is compatible with results obtained with conscious rats [5] but at variance with findings obtained in dogs $[7,20]$. In the dogs, pressure-dependent renin secretion was found mainly to occur within the autoregulatory range $[7,20]$ and it did not increase further when the renal artery pressure was reduced below $60 \mathrm{~mm}$ $\mathrm{Hg}[7,20]$. The reason for those differences between the pressure dependence of renin release in vitro and in the intact animal is not known. However, pressure modulation of renin secretion appears to require a basal flow to become effective. Thus, pressure-dependent renin release from rabbit afferent arterioles has only been found with a free-flow system allowing parallel changes of the perfusate flow [3], whereas pressure dependence was not preserved by using a similar stop-flow technique [29]. Since, in contrast to the in vivo situation, isolated perfused kidney preparations are characterized by a relatively high basal flow rate in the lower pressure range also, this could be a reason why we found pressure dependence to be preserved also at values lower than $60 \mathrm{~mm}$ $\mathrm{Hg}$.

Elevating the perfusion pressure above $100 \mathrm{~mm} \mathrm{Hg}$ only led to a slight increase of perfusate flow indicating that myogenic control of flow was preserved (Fig. 1). Within this autoregulatory range the pressure/renin secretion relationship was characterized by a plateau level with increasing perfusion pressure causing no further significant inhibition of renin release (Fig. 1). Within the plateau phase renin secretion was still regulatible, as indicated by the inhibitory effect of angiotensin II and by the stimulatory effect of isoproterenol (Figs. 3 and 8). A similar relationship between renin secretion and renal artery pressure with a slope, threshold pressure and a plateau phase has also been obtained in conscious dogs $[7,20]$ and rats $[5,17]$.

Our finding that autoregulation of renal flow was blunted by different organic calcium entry blockers (Fig. 1) is in good accordance with previous studies suggesting that influx of calcium into renal vascular smooth muscle cells through VOCC plays an essential role in the myogenic response to increasing renal artery pressure $[4,23,25]$. The prompt and long-lasting vasoconstrictor effect of Bay K 8644, a dihydropyridine calcium channel agonist [32], which is thought to enhance transmembrane calcium influx $[19,32]$, is also compatible with this concept (Fig. 7).

More unexpected was that three structurally different calcium antagonists did not alter renin secretion in the pressure range $40-160 \mathrm{~mm} \mathrm{Hg}$, which led to a dissociation of renin release from the myogenic control of flow (Fig. 1). Bay K 8644 also did not alter renin release from the isolated kidneys, not even if it had first been stimulated with isoproterenol (Fig. 8).

Under the assumption that VOCC in vascular smooth muscle cells and in renal juxtaglomerular cells should have similar pharmacological properties, the sum of our results suggests that VOCC are not essentially involved in the baroreceptor mechanism controlling renin secretion in the isolated rat kidney.

At a first view our findings and conclusions seem to be at odds with several reports suggesting an essential role of VOCC in the control of renin secretion from renal juxtaglomerular cells [9]. It must be noted, however, that the experimental evidence available on this question is already contradictory. For instance Hackenthal and Taugner [13] observed that $1 \mu \mathrm{M}$ Bay K 8644 caused a $50 \%$ reduction of basal renin release and a $10 \%$ increase in vascular resistance in the isolated perfused rat kidney, while Dietz [6] found a $60 \%$ increase in vascular resistance and no change of renin secretion under the same conditions. The latter author also observed no effect of Bay K 8644 on renin secretion stimulated by hypotension. With results very similar to our own (Figs. 4, 6), he also found that verapamil but not nifedipine at higher concentrations increased renin secretion at high pressures [6]. Roy et al. [28] reported that intrarenal infusion of verapamil in anaesthetized dogs caused an inhibition of renin secretion. Only in postischaemic papaverine-treated kidneys did they find a stimulation of renin secretion by 
verapamil [28]. Stimulatory effects of verapamil on renin secretion are usually seen at concentrations higher than $10 \mu \mathrm{M}$ (cf. [14]), a finding that was also obtained in this study (Fig. 6). Inhibition of VOCC by verapamil, however, occurs in the low micromolar concentration range as also seen in this study (Fig. 1). Recently it was shown that verapamil in the micromolar concentration range is capable also of blocking potassium channels in vascular smooth muscle cells [26]. Since potassium channels are predominant in JG cells [21] it can not be ruled out that stimulation of renin secretion by verapamil is due to interference with non-calcium channels.

Although nifedipine and related drugs significantly increased urinary sodium excretion, the possibility appears less likely that inhibition of renin release via the macula densa mechanism neutralized a direct stimulatory effect on JG cells by blocking calcium influx through VOCC. Thus, $50 \mu \mathrm{M}$ bumetanide, an inhibitor of the $\mathrm{Na}^{+}-\mathrm{K}^{+}-2 \mathrm{Cl}^{-}$cotransport [11], reduced renal vascular resistance and at the same time significantly increased urinary sodium excretion and renin release, suggesting that the macula densa transport function was effectively inhibited. However, even under those conditions nifedipine did not significantly affect, and in particular did not stimulate, renin secretion from isolated perfused kidneys (Fig. 5).

Taken together our findings indicate and thus confirm previous results that VOCC are essential mediators of the renal vascular myogenic response to pressure but they also suggest that VOCC are not essentially involved in the baroreceptor mechanism controlling renin secretion. Thus, the elucidation of this mechanism requires future work and we think that the isolated perfused rat kidney is a suitable model for the further investigation of this question. Our findings show that the cellular mechanisms mediating the control of renin secretion by pressure are fast-operating (Fig. 2). This characteristic may be helpful to narrow-down possible candidates for baroreceptor signals.

Acknowlegements. We wish to thank U. Vogel for expert technical assistance and C. Gasser and K. H. Goetz for doing the artwork. This study was supported by a grant of the Swiss National Science Foundation (31-26381.89).

\section{References}

1. Altura BM, Altura BT (1984) Comparative effects of nitrendipine and verapamil on isolated blood vessels of dogs. In: Scriabine A (ed) Nitrendipine. Urban \& Schwarzenberg, Baltimore, pp 293-309

2. Barajas L (1979) Anatomy of the juxtaglomerular apparatus. Am J Physiol 236:F333 - F 343

3. Bock HA, Hermle M, Brunner FP, Thiel G (1990) Evidence for a renin-baroreceptor mechanism in rabbit renal afferent arterioles (abstract). Kidney Int 37:353

4. Cohen AJ, Fray JSC (1982) Calcium dependence of myogenic renal plasma flow autoregulation: evidence from the isolated perfused rat kidney. J Physiol (Lond) 330:449 - 460

5. Conrad KP, Brinck-Johnson T, Gellai M, Valtin H (1984) Renal autoregulation in chronically catheterized conscious rats. Am J Physiol 247:F229-F233
6. Dietz JR (1986) Effects of a calcium channel agonist on renin release from perfused rat kidneys. Renal Physiol 9:279-286

7. Eide I, Loyning E, Kiil F (1973) Evidence for hemodynamic autoregulation of renin release. Circ Res $32: 237-245$

8. Fray JCS (1976) Stretch receptor model for renin release with evidence from perfused rat kidney. Am J Physiol 231 :936-944

9. Fray JCS (1980) Mechanism by which renin secretion from perfused rat kidneys is stimulated by isoprenaline and inhibited by high perfusion pressure. J Physiol (Lond) 308:1-13

10. Goldblatt H, Lynch J, Hanzel RF, Summerville WW (1934) The production of persistent elevation of systolic blood pressure by means of renal ischemia. J Exp Med 59:347-349

11. Greger R (1981) Ion transport mechanisms in thick ascending limb of Henle's loop of mammalian nephron. Physiol Rev 65:760-797

12. Haber $\mathrm{E}$ (1979) The renin-angiotensin system and hypertension. Kidney Int 15:427-444

13. Hackenthal E, Taugner R (1986) Hormonal signals and intracellular messengers for renin secretion. Mol Cell Endocrinol $47: 1-12$

14. Hackenthal E, Paul M, Ganten D, Taugner R (1990) Morphology, physiology, and molecular biology of renin secretion. Physiol Rev 70:1067-1116

15. Harder DR, Gilbert R, Lambard JH (1987) Vascular muscle cell depolarization and activation in renal arteries on elevation of transmural pressure. Am J Physiol 253:F778-F781

16. Ichihara $\mathrm{T}$, Matsumura $\mathrm{Y}$, Shinyama $\mathrm{H}$, Ohyama $\mathrm{T}$, Morimoto $S$ (1989) Effects of Bay K 8644 on renal function and renin secretion in anesthetized rats. Life Sci 44:1945-1953

17. Imagawa J, Miyauchi T, Satoh S (1984) Direct relationship between renal artery pressure and plasma renin activity in conscious rats. Jpn J Pharmacol 35:481-484

18. Johnson PC (1986) Autoregulation of blood flow. Circ Res $59: 483-495$

19. Kanmura Y, Itoh T, Kuriyama H (1984) Agonist actions of Bay $\mathrm{K} 8644$, a dihydropyridine derivative, on the voltage-dependent calcium influx in smooth muscle cells of the rabbit mesenteric artery. J Pharmacol Exp Ther 231:717-723

20. Kirchheim H, Ehmke H, Hackenthal E, Löwe W, Persson P (1987) Autoregulation of renal blood flow, glomerular filtration rate and renin release in conscious dogs. Pflügers Arch 410:441-449

21. Kurtz A, Penner R (1989) Angiotensin II induces oscillations of intracellular calcium and inhibits anomalous inward rectifying potassium current in renal juxtaglomerular cells. Proc Natl Acad Sci USA 86:3423a-3427

22. Lieberthal W, Stephens GW, Wolf EF, Rennke HG, Vasilevsky ML, Valeri CR, Levinsky NG (1987) Effect of erythrocytes on the function and morphology of the isolated perfused rat kidney. Renal Physiol 10:14-24

23. Loutzenhiser R, Epstein M (1985) Effects of calcium antagonists on renal hemodynamics. Am J Physiol 249: F 619-F 629

24. Matsumura Y, Sasaki Y, Shinyama H, Morimoto S (1985) The calcium channel agonist, Bay $\mathrm{K} 8644$, inhibits renin release from rat cortical slices. Eur J Pharmacol 117:369-372

25. Ono H, Kokubun H, Hashimoto K (1974) Abolition by calcium antagonists of the autoregulation of renal blood flow. NaunynSchmiedeberg's Arch Pharmacol 285:201-207

26. Pavenstädt H, Lindeman S, Lindeman V, Späth M, Kunzelmann K, Greger R (1991) Potassium conductance of smooth muscle cells from rabbit aorta in primary culture. Pflügers Arch $419: 57-68$

27. Rightsel WA, Okamura T, Inagami T, Pitcock DA, Taki Y, Brooks B, Brown P, Muirhead EE (1982) Juxtaglomerular cell culture contain renin, angiotensin I converting enzyme, and angiotensin I and II/III. Circ Res 50:822-829

28. Roy MW, Guthrie GP, Holladay FP, Kotchen TA (1983) Effects of verapamil on renin and aldosterone in the dog and rat. Am J Physiol 245:E410-E416

29. Salomonsson M, Skott O, Persson AEG (1991) Influence of intraluminal arterial pressure on renin release. Acta Physiol Scand $141: 285-286$ 
30. Schmidt FH (1961) Die enzymatische Bestimmung von Glukose und Fruktose nebeneinander. Klin Wochenschr 39:1244-1247

31. Scholz H, Kaissling B, Inagami T, Kurtz A (1991) Differential response of renin secretion to vasoconstrictors in the isolated perfused rat kidney. J Physiol (Lond) $441: 453-468$

32. Schramm M, Thomas G, Towart R., Franckowiak G (1983) Novel dihydropyridines with positive inotropic action through activation of $\mathrm{Ca}^{2+}$ channels. Nature 303:535-537

33. Schurek HJ, Alt JM (1981) Effect of albumin on the function. of perfused rat kidney. Am J Physiol 240:F 569 - F 576

34. Skinner SL, McCubbin JW, Page IH (1964) Control of renin secretion. Circ Res 15:64-76
35. Skott O, Briggs J (1987) Direct demonstration of macula densamediated renin secretion. Science 237:1618-1620

36. Taugner R, Bührle CP, Hackenthal E, Mannek E, Nobiling R (1984) Morphology of the juxtaglomerular apparatus and secretory mechanisms. Contrib Nephrol 43:76-101

37. Tobian L (1960) Interrelationship of electrolytes, juxtaglomerular cells, and hypertension. Physiol Rev 40:280-312

38. Zschiedrich H, Hofbauer KG, Baron GD, Hackenthal E (1975) Relationship between perfusion pressure and renin release in the isolated rat kidney. Pflügers Arch 360:255-266 